\title{
A Narrowband Corner Slot Patch Antenna for 2.4 GHz Wireless Radio Communications
}

\author{
M.Saravanan \#1, M.J.S.Rangachar *2

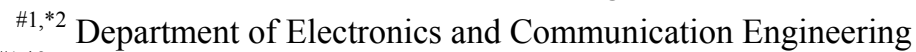 \\ ${ }^{\# 1, * 2}$ Hindustan Institute of Technology and Science, Chennai, India. \\ ${ }^{\# 1}$ msarawins@gmail.com \\ *2mjsranga@gmail.com
}

\begin{abstract}
A narrowband corner slot patch antenna has been designed for industrial, scientific, and medical radio band (ISM band) for short distance radio communication. These antennas are analyzed and are optimized using Ansoft High-Frequency Structure Simulator (HFSS). The objective is to shrink the size of the radiating patch element without compromising antenna performance. The proposed design is investigated under various parametric analyses and are compared. The overall size of the antenna is reduced by $32.8 \%$ when compared with traditional patch antenna available in the market. This can be achieved by introducing four slots inclined at $45^{\circ}$ in the radiating patch. The antenna provides a bandwidth of $25 \%$ in ISM band $(|\mathrm{S} 11| \leq 10 \mathrm{~dB})$ between $2.37 \mathrm{GHz}$ to $2.43 \mathrm{GHz}$. In addition, maximum Voltage Standing Wave Ratio (VSWR) value near to 1.0 and gain of $7.5 \mathrm{~dB}$ is achieved. Finally, good agreement has been obtained for using this proposed design for short distance radio communications.
\end{abstract}

Keyword - Patch antenna, ISM band, Return loss, Standing wave ratio.

\section{INTRODUCTION}

During last few decades, the scalability of embedded devices aids in greater interest in small wearable and handheld devices. This put huge demand reduction in the size of antenna used in those devices. Planar technology provides a promising solution to these demands. However, in order to meet global demand in miniature wireless gadgets, the size of the antenna has to be further reduced. A lot of studies have been conducted on planar antennas [1]. Most of the miniature devices use patch antenna which operates at ISM band for short distance communications which operates at $2.4 \mathrm{GHz}$ resonant frequency. So the proposed model is designed to operate at ISM band. Since the application requires narrow bandwidth with good gain characteristics, the antenna uses a dielectric substrate having permittivity $\varepsilon_{\mathrm{r}}=2.2$. Though microstrip antennas are compact, light weight, and ease of fabrication, the antenna achieves poor gain. So sufficient steps have been taken in order to improve the antenna gain [2]. Some of the techniques involve a reduction in edges [3] or by creating $\mathrm{U}$ - shaped slots in the radiating element [4]. However, these techniques provide a reduction in physical length of antenna only for few resonant frequencies. In some papers, miniaturization is achieved by meandering the radiating element of the patch antennas [5]. These antennas perturb the radiation pattern and also increase the complexity of fabrication. An introduction of shorting pin near to feed point is introduced in [6], which indirectly introduces the inductive effect in those antennas. In [7], reduces the antenna size from $0.5 \lambda$ to $0.25 \lambda$. However, it is not sufficient to fit in modern devices. A miniature in patch size is introduced in [8]. Since it uses multilayer substrates the thickness of the antenna is greatly increased.

In this paper, a narrowband corner slot patch antenna for short distance wireless communications is designed to cover $2.4 \mathrm{GHz}$ ISM band. The antenna uses roger duroid substrate for its low loss nature and the slots are carefully trimmed to operate at ISM bands. A complete parametric analysis is done by tuning physical dimension of the slot and traces the results with respect to operating frequencies. Simulation is done using HFSS, and the results are compared with existing traditional rectangular patch antenna.

\section{ANTENNA DESIGN METHOD}

The antenna geometry is shown in Fig. 1. The design uses low loss roger duroid 5880 dielectric substrates and is excited by a coaxial probe at position (Feed_x, Feed_y).

Four slots at each corner of the radiating element are incorporated to perturb the surface currents, which induces the inductive effect. The width (Slot_W) and Height (Slot_H) of the slots are varied for tuning the operating frequency. 


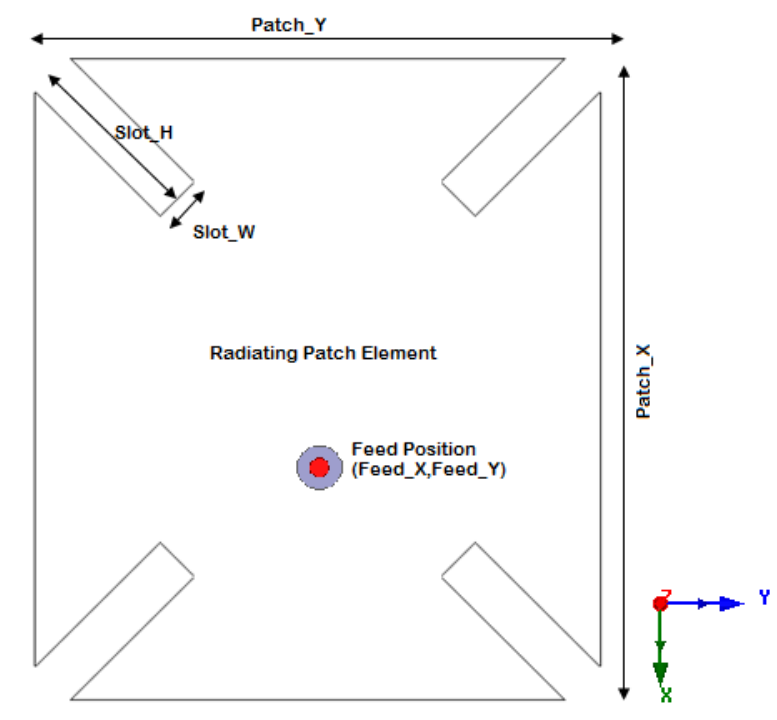

Top View

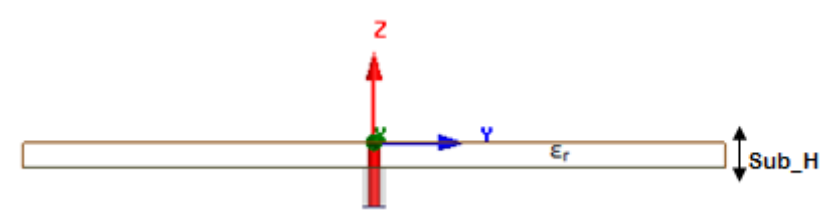

Side View

Fig. 1 Configuration of Corner slot patch antenna

Fig. 2(a) shows an equivalent circuit of a traditional rectangular patch antenna and proposed corner slot. The operating frequency is determined from the tank circuit components L1C1. At that resonant frequency, the impedance of LC component is zero, such that the antenna is purely resistive. i.e., reactive components are zero. The characteristic impedance of the coaxial cable is matched with input impedance by properly placing the position of feeder point in the patch element.
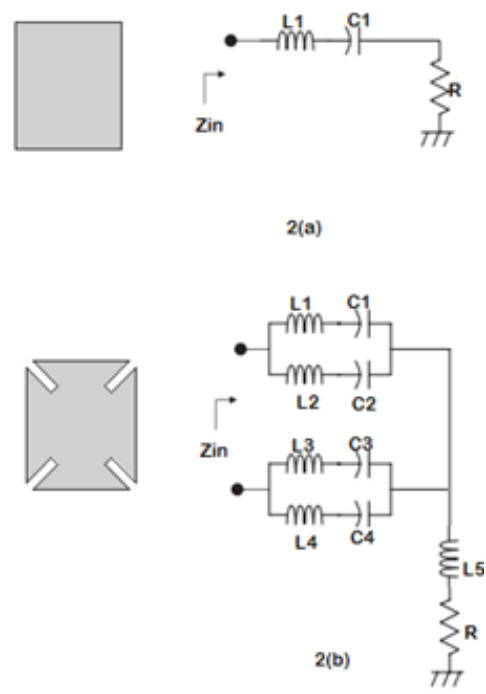

Fig. 2 Equivalent circuits of (a) rectangular patch and (b) Corner slot patch antenna.

A modified structure of traditional patch antenna with four corner slots is shown in figure 2(b). Analysis of modified structure gives characteristic impedance given below.

$$
Z_{\text {in }}=R+L_{5}+\left(j \frac{\left(\omega L_{1}-1 / \omega C_{1}\right)\left(\omega L_{2}-1 / \omega C_{2}\right)}{\omega\left(L_{1}-L_{2}\right)-\left(1 / \omega C_{1}-1 / \omega C_{2}\right)}\right) \|\left(j \frac{\left(\omega L_{3}-1 / \omega C_{3}\right)\left(\omega L_{4}-1 / \omega C_{4}\right)}{\omega\left(L_{3}-L_{4}\right)-\left(1 / \omega C_{3}-1 / \omega C_{4}\right)}\right)
$$

At the resonant point, the tank circuit components resonate and are matched in such a way that the imaginary reactive components cancels each other and leaving pure resistive components in characteristic impedance. 


\section{III.PARAMETRIC STUDY}

A low loss dielectric substrate Roger duroid 5880 of permittivity $\varepsilon_{\mathrm{r}}=2.2$ is selected to obtain a solid radiating structure operating at ISM band. The height and width of the slots are tuned to obtain the desired characteristics. The design is excited by $50 \Omega$ coaxial feed at position (Feed_X, Feed_Y). The inner conductor is punched through the substrate and is made contact with the radiating element while the outer conductor jacket is soldered to the ground. Entire design process validated using HFSS tool. The parameters considered for tuning are Slot_W and Slot_H and its effect over operating frequency is studied.

Figure 3(a) shows the effect of the width of the slot over operating frequency. The slot width is varied from $0.2 \mathrm{~cm}$ to $0.4 \mathrm{~cm}$ with a step size of $0.25 \mathrm{~cm}$. As the width of the slot increases the operating frequency shifts from lower band to higher band. This is due to the fact the overall are of the radiating element decreases with increase in slot width which in turn shift the frequency to a higher band. From the figure 3(a) the optimum dimension of the slot width for the desired operating band is determined.

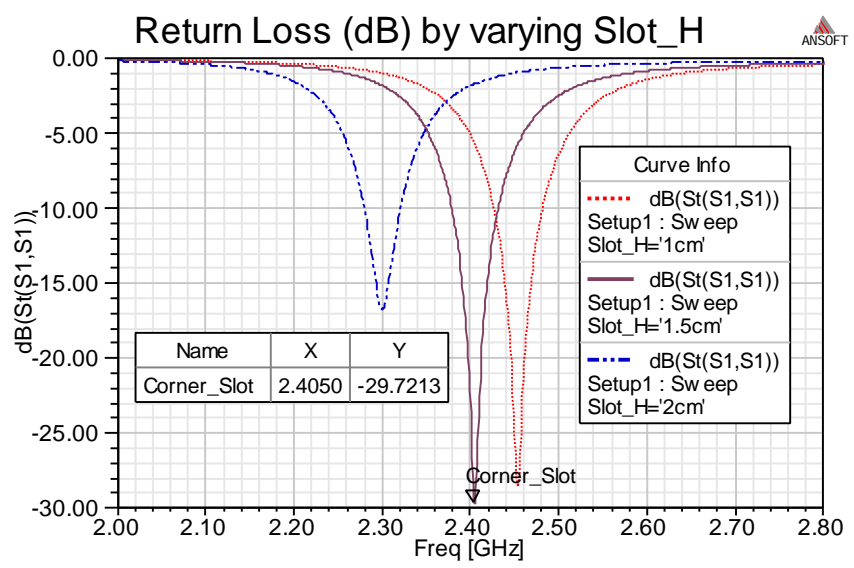

Fig. 3(b) Return Loss (dB) by tuning Slot_H

Figure 3(b) shows the effect of length of the slot over operating frequency. The slot height is varied from 1 $\mathrm{cm}$ to $2 \mathrm{~cm}$ with a step size of $0.5 \mathrm{~cm}$. As the length of the slot increases the operating frequency shifts from higher band to lower band. From the figure 3(b) the optimum dimension of the slot length for the desired operating band is determined.

Based on the parametric analysis of proposed design, the optimum physical dimensions of slots are calculated and are given in Table I.

TABLE I. ANTENNA PhySiCAL DimENSIONS

\begin{tabular}{|l|l|}
\hline Parameters & Dimensions in cm \\
\hline Patch_X & 3.8 \\
\hline Patch_Y & 3.325 \\
\hline Sub_H & 0.32 \\
\hline Slot_H & 1.5 \\
\hline Slot_W & 0.3 \\
\hline (Feed_X,Feed_Y) & $(0.5,0)$ \\
\hline
\end{tabular}

\section{IV.RESULTS AND DISCUSSIONS}

From parametric study, the slot width and slot height are determined and the performance of the antenna is simulated and is compared with the traditional rectangular patch antenna. Figure 4(a) shows return loss in $\mathrm{dB}$ and figure 4(b) shows Voltage standing wave ratio. The feeder is given at $10 \mathrm{~mm}$ from the center of patch, at which the resistance is fairly low in order to match the impedance of coaxial feed cable. Hence the design gives return loss of about $-29.7213 \mathrm{~dB}$ as shown in Figure 4(a) and has a bandwidth of $25 \%$ in ISM band $(|\mathrm{S} 11| \leq 10 \mathrm{~dB})$ operating between $2.37 \mathrm{GHz}$ and $2.43 \mathrm{GHz}$. The model also gives a good VSWR of about $0.5675(\mathrm{VSWR}<1)$ as shown in Figure 4(b). 


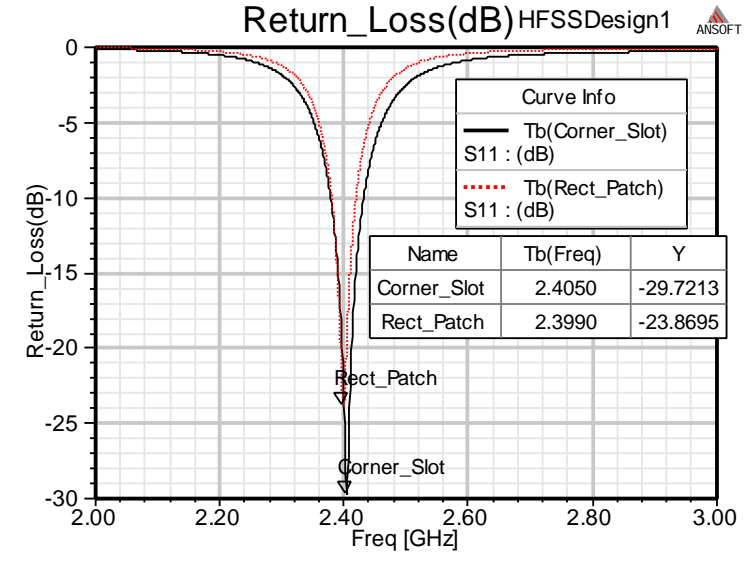

Fig. 4(a) Return Loss (dB)

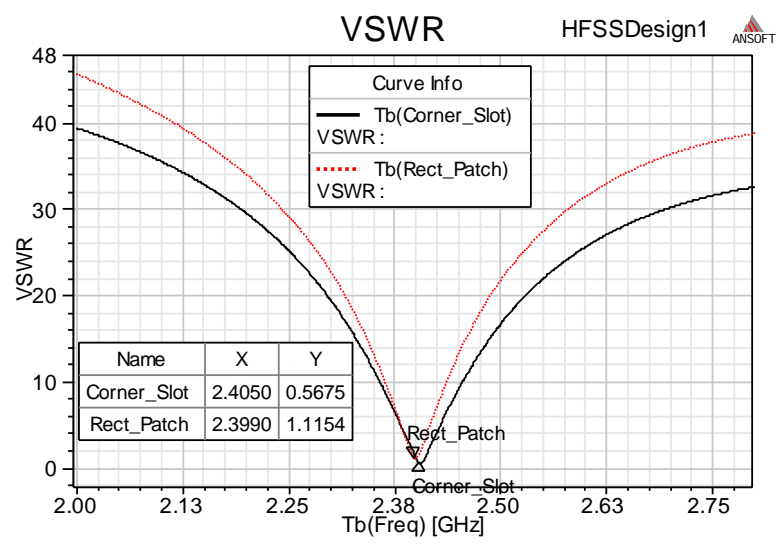

Fig. 4(b) VSWR

The feeder location is properly selected in such a way that the input impedance $(50 \Omega)$ of the coaxial cable has to match with a characteristic impedance of the antenna. This can be achieved by tuning inductive component to match with the capacitive component.

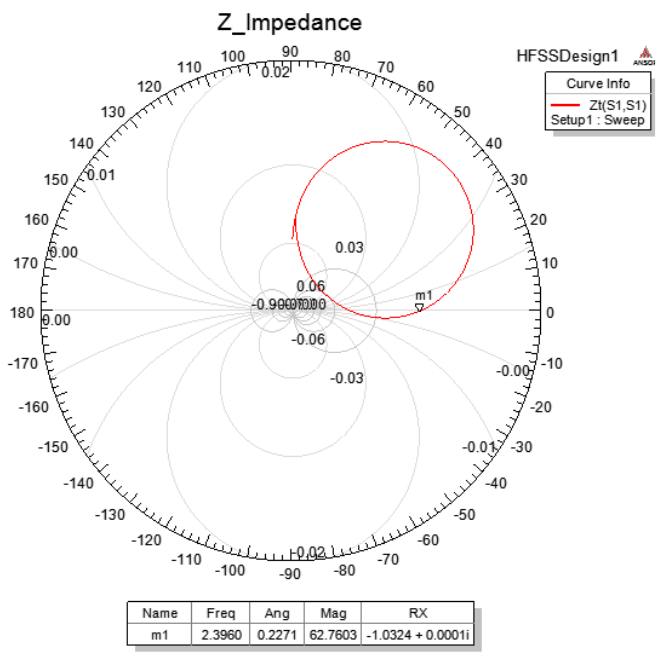

Fig. 5. Z Impedance

Figure 5 shows the impedance plotted over Smith chart where the reactive component becomes zero, and the antenna becomes purely resistive. From figure 5, the reactive component of the antenna approaches zero which ensure that the antenna is purely resistive.

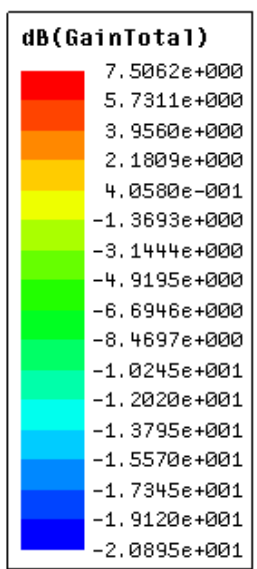

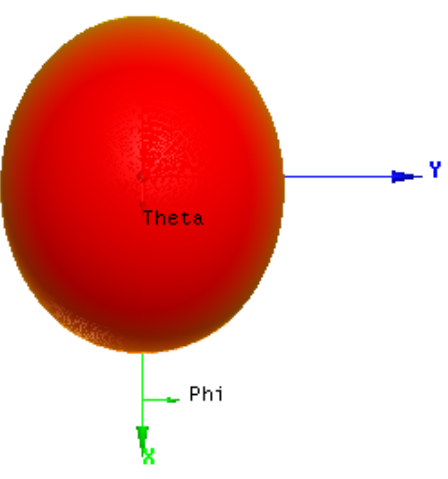

Fig. 6(a) Total gain in $\mathrm{dB}$

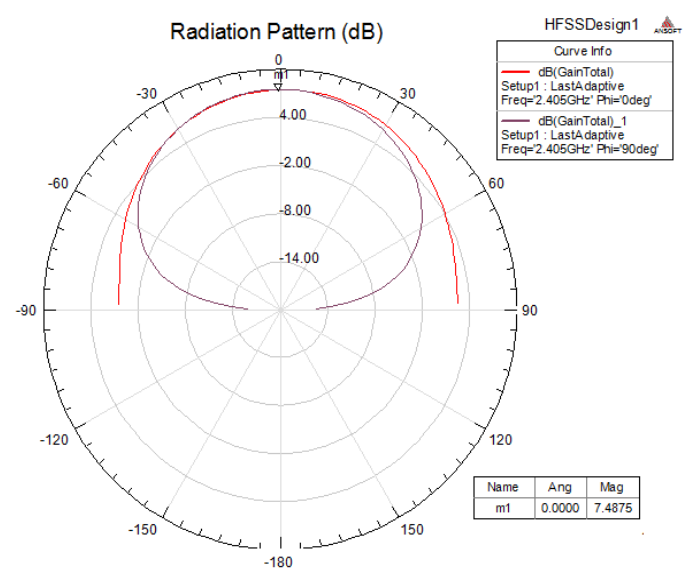

Fig. 6(b) Radiation Pattern 
The gain of the antenna is improved by selectively tuning the feeder location of the coaxial cable to match the impedance and hence the design gives a gain of about $7.5 \mathrm{~dB}$ at operating frequency and also gives near omnidirectional radiation pattern in azimuthal angle as shown in figure 6 given below. The performance of the antenna is antennas is compared with traditional rectangular patch antenna and are given in Table II below.

TABLE II. Performance Comparison of antenna parameters

\begin{tabular}{|l|l|l|}
\hline \multirow{2}{*}{\multicolumn{1}{|c|}{ Parameter }} & \multicolumn{2}{c|}{ Specifications } \\
\cline { 2 - 3 } & \multicolumn{1}{c|}{ Rectangular Patch } & \multicolumn{1}{c|}{ Corner Sot } \\
\hline Patch Area & $\begin{array}{l}4.74 \mathrm{~cm} \times 3.97 \mathrm{~cm} \\
=18.817 \mathrm{~cm}^{2}\end{array}$ & $\begin{array}{l}3.8 \mathrm{~cm} \times 3.325 \mathrm{~cm} \\
=12.635 \mathrm{~cm}^{2}\end{array}$ \\
\hline Return Loss $(\mathrm{dB})$ & $-23.8695 \mathrm{~dB}$ & $-29.7213 \mathrm{~dB}$ \\
\hline Impedance $(\Omega)$ & $1.086+\mathrm{j} 0052 \Omega$ & $1.034+\mathrm{j} 0001 \Omega$ \\
\hline Gain $(\mathrm{dB})$ & $7.43 \mathrm{~dB}$ & $7.5 \mathrm{~dB}$ \\
\hline Bandwidth & $23 \%$ & $25 \%$ \\
\hline
\end{tabular}

\section{CONCLUSION}

A narrowband corner slot patch antenna has been designed for short distance wireless communications. The antenna incorporates slots at the corners of the radiating patch which reduce the size by $32.8 \%$ when compared with existing rectangular patch antenna. The design achieves a reflection coefficient of $-29.7213 \mathrm{~dB}$. The operating frequency can be easily tuned by varying the length and width of the slots. For the given slot dimensions, the antenna operates between $2.37 \mathrm{GHz}$ to $2.43 \mathrm{GHz}$ providing a bandwidth of $25 \%$ in ISM band $(|\mathrm{S} 11| \leq 10 \mathrm{~dB})$ and providing a gain of $7.5 \mathrm{~dB}$. Thus the designed antenna model meets necessary demands with a reduction in patch area and thereby making it suitable for short distance wireless communications.

\section{REFERENCES}

[1] Constantine A. Balanis, Antenna Theory: Analysis and Design, John Wiley \& Sons, 2016.

[2] Ahmed A. Kishk and Wei Huang, "Size-Reduction Method for Dielectric-Resonator Antennas", IEEE Antennas and Propagation Magazine, Vol. 53, No.2, April 2011.

[3] Z. D. Liu, P. S. Hall, and D. Wake, "Dual-Frequency Planar Inverted-F Antenna," IEEE Transactions on Antennas and Propagation, AP-45, 10, October 1997, pp. 1451-1458.

[4] C. L. Mak, R. Chair, K. F. Lee, K. M. Luk, and A. A. Kishk, "Half V-Slot Patch Antenna with Shorting Wall," Electronics Letters, 2003, pp. 1779-1780

[5] A. Kishk, K. F. Lee, W. C. Mok, and K. M. Luk, "A Wide Band Small Size Microstrip Antenna Proximately Coupled to a Hook Shape Probe," IEEE Transactions on Antennas and Propagation, AP- 52, I, January 2004, pp. 59- 65.

[6] R, Waterhouse, "Small Microstrip Patch Antenna," Electronics Letters, April 1995, pp. 604-605

[7] J. Wang, J. Zhao, and J.-L. Li, "Compact UWB bandpass filter with triple notched bands using parallel U-shaped defected microstrip structure," Electron. Letters, vol. 50, no. 2, pp. 89-91, Jan. 2014.

[8] S. Pinhas and S. Shtrikman, "Comparison between computed and measured bandwidth of quarter-wave microstrip radiators," IEEE Transactions on Antennas Propagation, vol. 36, no. 11, pp. 1615-1616, 1988.

[9] Whittow. W. "Microstrip patch antennas with 3-dimensional substrates". Antennas and Propagation Conference (LAPC), 2012, pp. $1-5$. 